\title{
Feasibility Study Evaluating Four Weeks Stochastic Resonance Whole-Body Vibration Training with Healthy Female Students
}

\author{
Slavko Rogan (Corresponding author) \\ Bern University of Applied Sciences, Health, Bern, Switzerland \\ AfiPT, Akademie für integrative Physiotherapie und Trainingslehre, Grenzach-Wyhlen, Germany \\ Lindenrain 4, 3008 Bern, Switzerland; Phone: +41 3184835 56, E-mail: slavko.rogan@bfh.ch \\ Lorenz Radlinger \\ Bern University of Applied Sciences, Health, Bern, Switzerland \\ E-mail: lorenz.radlinger@bfh.ch \\ Cornelia Portner-Burkhalter \\ Bern University of Applied Sciences, Health, Bern, Switzerland \\ Alice Sommer \\ Bern University of Applied Sciences, Health, Bern, Switzerland \\ Dietmar Schmidtbleicher \\ Goethe-University, Institute of Sport Sciences, Frankfurt/Main, Germany \\ E-mail: Schmidtbleicher@sport.uni-frankfurt.de
}

Received: 21-06- 2013

Accepted: 24-07- 2013

Published: 30-07- 2013

doi:10.7575/aiac.ijkss.v.1n.2p.1

URL: http://dx.doi.org/10.7575/aiac.ijkss.v.1n.2p.1

\begin{abstract}
This study assessed the feasibility of stochastic resonance whole-body vibration (SR-WBV) training and its impact on isometric maximal voluntary contraction (IMVC), isometric rate of force development (IRFD) and a drop jump test (DJ) in healthy female students. Twelve participants were randomised to static squats during SR-WBV $6 \mathrm{~Hz}$, noise level 4 , over 4 weeks or to a control group (no training). Feasibility outcomes included the number of students agreeing to participate, the number of drop-outs, the adherence to the SR-WBV and the evaluation of the protocol. Secondary outcomes were IMVC, IRFD and DJ. Results: Among 35 eligible students, 12 agreed to participate and two dropped out. The adherence was 41 of 60 possible sessions. There were moderate to large, but statistically non-significant, gains in the secondary outcomes. Conclusion: These results suggest that such a study would be feasible although with some modifications such as a better familiarisation to the DJ.
\end{abstract}

Keywords: Pilot study, compliance, isometric maximal voluntary contraction, isometric rate of force development, stretch-shortening cycle

\section{Introduction}

The literature shows moderate evidence that whole-body vibration (WBV) improves strength and power in healthy persons or in patients. Two basic forms of whole-body vibration can be distinguished: sinusoidal whole-body vibration (S-WBV) and whole-body vibration with stochastic resonance (SR-WBV) (Rogan \& Hilfiker, 2012). During S-WBV the device vibrates vertically or side alternating with frequencies from 20 to $50 \mathrm{~Hz}$ and amplitudes from 2 to $6 \mathrm{~mm}$ (Cochrane, 2011). During SR-WBV, participants stand on two platforms that vibrate independently between 1 and 12 $\mathrm{Hz}$ and (Rogan, Radlinger, et al., 2012).

Some studies showed positive effects after S-WBV on muscle strength (Marin \& Rhea, 2010a, 2010b). An advantage of WBV training is that it is easy to use with minimal effort. Furthermore, improvements on strength and power can be reached within a short time frame (Cardinale \& Bosco, 2003; Rogan \& Hilfiker, 2012). The theories by which this impact occurs are thought to be neuromuscular in origin. The vibration stimuli produce small changes in the muscletendon complex (Cochrane, Loram, Stannard, \& Rittweger, 2009), activate the muscle spindles with stimulation of the Ia-afferents, facilitating the alpha motor neuron output and contracting the extrafusal muscle fibres (Roelants, Delecluse, Goris, \& Verschueren, 2004). 
In contrast to S-WBV, stochastic signal components cause a simple collection and processing by the nervous system (Haas, 2006). Furthermore, SR-WBV has the advantage that the nerve cells cannot adapt (Haas, Turbanski, Kaiser, \& Schmidtbleicher, 2004; Haas, Turbanski, \& Schmidtbleicher, 2007).

A few studies examined immediate effects after SR-WBV, mainly on postural control (Haas, Buhlmann, Turbanski, \& Schmidtbleicher, 2006; Haas, Turbanski, Kessler, \& Schmidtbleicher, 2006; Turbanski, Haas, Schmidtbleicher, Friedrich, \& Duisberg, 2005). Research on SR-WBV and its impact on muscle strength is sparse. One long-term study investigated the effect after SR-WBV training on muscle strength during chair rising in untrained elderly persons (Rogan, Hilfiker, Schmid, \& Radlinger, 2012). This study showed that the SR-WBV group improved more than the sham-WBV group.

Given the dearth of published studies in this topic, it seems justified to assess the feasibility of SR-WBV training on healthy young people in a first step. The findings of this feasibility study can inform a main phase III study, i.e. a study that will prove the effectiveness compared with placebo or other therapies (Thabane et al., 2010).

The goal of the current feasibility study was to perform a phase II trial to evaluate the impact after SR-WBV intervention on healthy students. Phase II trials are studies on safety and tolerability in the target population and first investigations study of effect and apportioning (Thabane et al., 2010). This feasibility study aimed (a) to examine the feasibility objectives of recruitment and randomisation process, compliance, safety and investigation protocol, and (b) to evaluate the impact of SR-WBV intervention on isometric maximal voluntary contraction (IMVC), isometric rate of force development (IRFD) and a drop jump test (DJ).

\section{Methods}

The present feasibility study is based on the guidelines of Thabane et al. (2010). This guideline described how to design and report the results of feasibility studies.

\subsection{Design}

This randomised study involved an intervention group (IG) and a control group (CG) on a pretest-posttest design with no blinding of the participants and no blinding of the assessors. It examined the feasibility and effects on IMVC, IRFD of the lower-limb muscles and DJ. The participants in the IG received 1-minute vibration with $6 \mathrm{~Hz}$, noise level 4, over 5-sets with 1-minute of rest in between (Bosco et al., 1999; Rogan, Hilfiker, et al., 2012) 3-times a week for 4 weeks with a total of 10 exercise sessions. The participants of the CG did not conduct any SR-WBV or other training sessions. They went to their normal everyday employment. Outcomes were measured at baseline and after 4 weeks. Figure 1 shows the study diagram.

\subsection{Participants}

Twelve healthy female students aged between 20 to 30 years participated in this feasibility study. Any participant who had acute health problems such as acute injuries, musculoskeletal problems or infections was excluded.

\subsection{Primary outcome: Criteria of success}

According to Thabane et al. (2010), the criteria for success were based on the primary feasibility objective and focused on the recruitment and randomisation process, compliance, safety, and the investigation protocol to the SR-WBV intervention. The feasibility criteria were based on the pilot study of Rogan et al. (2012) who carried out a feasibility study of SR-WBV intervention for chair rising with untrained elderly. Following approach and items have been defined:

Recruitment of one fifth of students that were eligible for the SR-WBV intervention session, a $10 \%$ attrition, and $90 \%$ adherence to the SR-WBV session were acceptable for the authors.

The recruitment process was carried out first by a verbal information session. The participants were issued with information sheets about the investigation process, the inclusion and exclusion criteria, as well as the experimental risk and benefit. This current feasibility study was performed according to the latest version of the declaration of Helsinki. Written consent was obtained from all students prior to enrolment in the feasibility study.

For the evaluation of the inclusion rate, we documented the number of the whole cohort of students and calculated the inclusion rate (i.e. those eligible and willing to participate divided by all students) (Rogan et al. 2012).

The non-blinded participants were randomly assigned to either IG or CG after the completion of all baseline assessments. The order of the measurements was randomised at pre- and post-test.

For attrition, the number of the participants lost during the intervention program was recorded. For adherence, the number of sessions a participant attended participated was recorded. An attendance list was created in order to record the attendance.

For safety, the participants were interviewed on their well-being, feelings of stability and for adverse effects such as dizziness or pain during vibration. The responses for well-being and feeling of stability were: 1. worse, 2. the same, 3 . better. As soon as the participant replied "worse", we asked about dizziness or pain.

\subsubsection{Investigation process}

Prior to the SR-WBV intervention, a standardised five-minute warm-up on a bicycle ergometer (Thumb electronic DIN 32932/A, Daum electronic GmbH, Fürth, Germany) was performed (Rees, Murphy, \& Watsford, 2008) at 100 watts 
(Bosco et al., 1999; Haas, Turbanski, \& Schmidtbleicher, 2002; Marin, Bunker, Rhea, \& Ayllon, 2009).

The participants were familiarised with the SR-WBV device one week prior to the feasibility study. For the stochastic whole-body vibration, a Zeptor med ${ }^{\circledR}$ vibration device (Frei Swiss AG, Zürich, Switzerland) was used. Its footplates moved actively up and down, passively forward/backward and left/right. The participants stood barefoot in a $100^{\circ}$ squat position (Bosco et al., 1999; Cormie er al. 2006; Marìn et al., 2009), and kept their arms crossed above their chest. The examiner verified the knee angle with a goniometer (European Mathys Orthopaedics, Bettlach, Switzerland).

\subsection{Secondary outcome}

A dynamometer measured the IMVC and the IRFD of the knee extensors of the non-dominant leg. IMVC (N) and IRFD $(\mathrm{N} / \mathrm{s})$ for leg extension was measured three times for five seconds (Bogaerts et al., 2009) with a break of 15 seconds between the measurements (Schlumberger \& Schmidtbleicher, 2000). The participants were seated on a dynamometer chair with $90^{\circ}$ knee flexion. A sling was attached at the distal end of the tibia, linked to a one-dimensional strain gauge, which was calibrated in N (Mebes et al., 2008). After the instruction "three - two - one - Go", the participants had to extend their knee as fast as possible (IRFD) and to continue to push isometrically as strongly as possible for five seconds (IMVC). Data were collected by a force transducer (KM 1500S; Megatron, Munich, Germany). The analogue signal was routed through an measurement amplifier (UMV, uk-labs, Kempen, Germany), digitised via a 12-bit AD converter card (Meilhaus ME-2600i, SisNova Engineering, Switzerland) and analysed using Analog Digital Signal Processing software (ADS, uk-labs, Kempen, Germany). Force-time signals were filtered using a digital low-pass filter (2nd order Butterworth) with a cut-off frequency of $30 \mathrm{~Hz}$. The MVC was extracted from the participants' individual force-time curves as peak value of strength. The IRFD was extracted at the steepest rise in the force-time curve (IRFD $(\mathrm{N} / \mathrm{s})=\Delta$ force $(\mathrm{N}) / \Delta$ time (s)) (Aagaard \& Bangsbo, 2006). The best value from the three trials of IMVC or IRFD was taken (Bosco et al., 1999; de Ruiter et al. 2003).

A drop jump (DJ) was used to determine the fast stretch-shortening cycle (F-SSC). For this purpose, the participants stood on a $40 \mathrm{~cm}$ box placed $20 \mathrm{~cm}$ from the force plates (Viitasalo et al.; Voelzke et al. 2012). The participants dropped as vertically as possible from the box onto the force plate with extended knees. After landing on the force plate, the participants immediately jumped as high as possible straight up in the air and landed back on the force plate. The hands had to stay placed on the hips. The total ground contact time (GCT; in milliseconds: ms) during a single DJ (without landing phase) was measured and the vertical jump altitude (VJH; in millimeters: $\mathrm{mm}$ ) was calculated. GCT and VJH were measured using a force plate (Type 9286BA, Kistler, Winterthur, Switzerland) that was embedded in a wooden walkway. The analogue force-time signal was collected at a rate of $1 \mathrm{kHz}$ using a 12-bit A/D converter (Meilhaus ME2600i; SisNova Engineering, Zug, Switzerland) and the software package "ADS" version 1.12 (uk-labs, Kempen, Germany). In order to obtain the output value GCT (ms) and VJH (mm) for the F-SSC, the values from two DJs were averaged.

\subsection{Statistical analysis}

The results are described as mean $\pm \mathrm{SD}$, as well as median and interquartile range (IQR). For inter-group comparisons (IG vs. CG), Mann-Whitney U test and for intra-group comparisons (pretest vs. posttest) Wilcoxon signed rank tests were used. A P-value $<.05$ was defined as statistically significant. Effect sizes (ES) for the non-parametric tests were calculated with the equation $\mathrm{r}=\mathrm{Z} / \sqrt{ } \mathrm{N}$ for within and between groups differences. An effect size of 0.1 was considered a "small" effect, $>0.3$ a "medium" effect and $>0.5$, a 'large' effect (Corder \& Foreman, 2009). Participants' compliance to the treatment protocol was calculated as: Number of vibration sessions multiplied by 100 divided by the total number of possible vibrations (Rogan et al. 2012).

The data were analysed using the statistical package program IBM SPSS Version 19 (SPSS, Inc., Chicago, USA) and Microsoft Excel 2007 (Microsoft Corporation, Redmond, USA). For the post-hoc analysis of the power the program G*Power 3 was used (Faul et al. 2004).

\section{Results}

\subsection{Recruitment}

Figure 1 summarises the flow through the study. The verbal information sessions were attended by 40 of 44 possible candidates. Nine students were excluded because they were male. Due to the lack of further interest, 15 potential candidates were rejected. The remaining four candidates were sick or injured, resulting in 12 students that were eligible to participate and that consented to participate in this feasibility study. This resulted in a recruitment rate of $35 \%$ for the total sample frame ( $\mathrm{n}=35$ female students). The inclusion rate with 12 participants was $100 \%$. The anthropometric characteristics are represented in Table 1. 


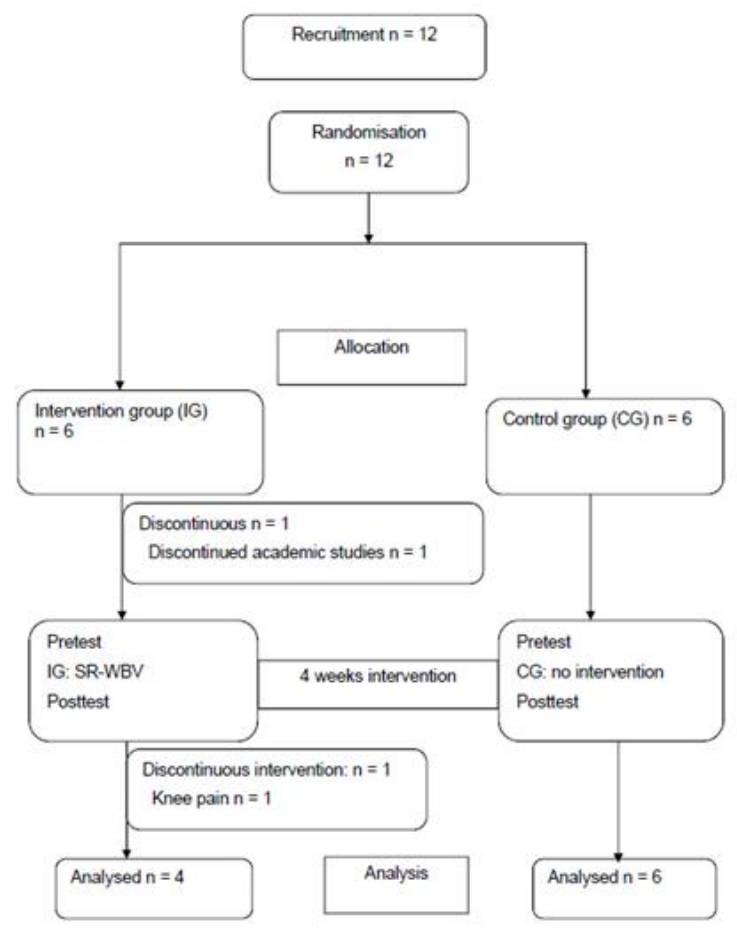

Figure 1. Flow Chart of the feasibility study

Table 1. Characteristics of the female students at baseline. Values are in means \pm SD

\begin{tabular}{lll}
\hline & SR-WBV $(\mathrm{n}=6)$ & CG $(\mathrm{n}=6)$ \\
\hline age (years) & $22.4 \pm 0.9$ & $22.8 \pm 2.7$ \\
height $(\mathrm{cm})$ & $166.05 \pm 4$ & $165 \pm 9$ \\
weight $(\mathrm{kg})$ & $61.8 \pm 8.4$ & $59.8 \pm 9.8$ \\
BMI $\left(\mathrm{kg} \mathrm{x} \mathrm{m}^{-2}\right)$ & $22.5 \pm 2.55$ & $59.8 \pm 9.75$ \\
\hline
\end{tabular}

One participant finished her studies before the start of the intervention and therefore did not participate in the SR-WBV. After three training sessions, another participant developed acute knee pain during the SR-WBV. The severity of this pain was so high that the starting position could not be taken on the SR-WBV device and the participant was excluded. The attrition rate was $17 \%$. Two of the remaining four participants performed all training sessions; the other two completed nine of ten training sessions. The adherence rate is $68.3 \%$ (41 of 60 training sessions). Two participants complained of dizziness after the training session on the SR-WBV device.

Significant improvement was determined in the CG for VJH only. Table 2 shows the mean and SD and median (IQR) for the variables of IMVC, IRFD and DJ. 
Table 2. Mean, standard deviation (SD), Median and IQR pretraining and posttraining scores for IG and CG

(secondary outcomes)

\begin{tabular}{|c|c|c|c|c|c|}
\hline & $\begin{array}{l}\mathrm{IG}(\mathrm{n}=4) \\
\text { mean } \pm \mathrm{SD}(\text { median }+\mathrm{IQR})\end{array}$ & $\begin{array}{l}\text { P } \\
\text { Within } \\
\text { groups }\end{array}$ & $\begin{array}{l}\text { CG }(\mathrm{n}=6) \\
\text { Median (IQR) }\end{array}$ & $\begin{array}{l}\mathrm{P} \\
\text { Within } \\
\text { grouns }\end{array}$ & $\begin{array}{l}\text { P } \\
\text { Between groups } \\
\text { (posttraining) }\end{array}$ \\
\hline & & $\begin{array}{l}\text { ES } \\
\text { (power) }\end{array}$ & & $\begin{array}{l}\text { ES } \\
\text { (power) }\end{array}$ & ES (power) \\
\hline \multicolumn{6}{|l|}{ IMVC, $(\mathrm{N})$} \\
\hline pretraining & $349 \pm 28 ; 362(325-395)$ & 0.273 & $416 \pm 63 ; 425(356-454)$ & 0.917 & 0.092 \\
\hline posttraining & $395 \pm 60 ; 436(344-457)$ & $\begin{array}{l}0.54 \\
(0.11)\end{array}$ & $409 \pm 43 ; 410(363-431)$ & $\begin{array}{l}0.05 \\
(0.05)\end{array}$ & $0.38(0.11)$ \\
\hline \multicolumn{6}{|c|}{$3547+1133 \cdot 3050(2369-4285)$} \\
\hline $\begin{array}{l}\text { pretraining } \\
\text { posttraining }\end{array}$ & $3578 \pm 873 ; 3367(3044-5188)$ & $\begin{array}{l}0.54 \\
(0.11)\end{array}$ & $4031 \pm 920 ; 3625(3205-4316)$ & $\begin{array}{l}0.50 \\
(0.16)\end{array}$ & $0.03(0.05)$ \\
\hline \multicolumn{6}{|l|}{$\mathrm{VJH},(\mathrm{mm})$} \\
\hline pretraining & $260 \pm 0.9 ; 250(210-310)$ & 0.068 & $260 \pm 0.4 ; 250(230-310)$ & $0.027^{*}$ & 0.792 \\
\hline $\begin{array}{l}\text { post } \\
\text { training }\end{array}$ & $310 \pm 0.5 ; 310(260-340)$ & $\begin{array}{l}0.90 \\
(0.23)\end{array}$ & $330 \pm 0.6 ; 340(290-390)$ & $\begin{array}{l}0.90 \\
(0.40)\end{array}$ & $0.38(0.11)$ \\
\hline \multirow{2}{*}{$\begin{array}{l}\text { GCT, }(\mathrm{ms}) \\
\text { pretraining } \\
\text { posttraining }\end{array}$} & $390 \pm 0.4 ; 370(265-435)$ & 0.144 & $450 \pm 0.5 ; 430(215-474)$ & 0.492 & 0.126 \\
\hline & $450 \pm 0.1 ; 450(410-460)$ & $\begin{array}{l}0.54 \\
(0.12)\end{array}$ & $460 \pm 0.6 ; 450(440-525)$ & $\begin{array}{l}0.41 \\
(0.13)\end{array}$ & $0.25(0.08)$ \\
\hline
\end{tabular}

*Statistically significant difference $(p<.05)$ after pre and post intervention

$\mathrm{IMVC}=\mathrm{IMVC}=$ isometric maximum voluntary contraction; $\mathrm{IRFD}=$ isometric rate of force development;

$\mathrm{VJH}=$ vertical jump height; GCT $=$ ground contact time

$\mathrm{N}=$ Newton; $\mathrm{N} / \mathrm{s}=$ Newton/seconds; $\mathrm{ms}=$ milliseconds

$\mathrm{ES}=$ effect size; P- values refer to interactions from Wilcoxon signed rank test and Mann-Whitney U test 


\section{Discussion}

The current study aimed (a) to evaluate feasibility objectives such as the recruitment and randomisation process, compliance, safety and the investigation protocol and (b) to analyse the impact of SR-WBV intervention on IMVC and IRFD and DJ. According to Thabane et al. (2010), the focus in a feasibility study is not primarily on the statistical analysis of effects. This feasibility study represents a validation phase preceding an intervention study that will evaluate its effects on muscle strength after SR-WBV intervention in young female participants. The main findings are that such a study will be feasible but would need modifications, which will be discussed below.

It is crucial to evaluate what the consent rate will be for participants entering a study (Burrows et al., 2001). This is important for planning how long it will take to recruit enough patients into the study (Lancaster, Dodd, \& Williamson, 2002). The recruitment for this feasibility study was carried out in a verbal presentation of the proposed research at the beginning of a lecture at a University. Afterwards, the information form was distributed. The target to recruit one fifth of the students could be reached. The recruitment form via personal presentation can be recommended. However, when considered the recruitment rate relative to the total number of female students $(n=35)$, the recruitment rate of $35 \%$ is low. These findings indicate that the recruitment process must be adapted to the situation. For future studies, multiple verbal information sessions should be performed to ensure that more students take part. In addition, information letters should also be distributed before and after the presentation.

In the next study, allocation should be concealed and testing should be performed blinded (Scherfer, 2006). It cannot be excluded that the examiner gives more attention to some volunteers than others. Furthermore, the psychological component might have had an impact, especially in the posttest because the participants in the intervention group were under some pressure to achieve better results than the control group. Two participants of the intervention group mentioned this before the tests.

The compliance in this feasibility study was not optimal. One participant developed knee pain after three SR-WBV interventions, this might be caused by the knee angle of $100^{\circ}$. In untrained individuals, this seems to lead to overloading the muscular and ligamentous structures. De Ruiter et al. (2003) described in their study that participant developed shin splints after two weeks of S-WBV. The participants stood on the vibration device with a knee angle of $110^{\circ}$ for more than 60 seconds over five to eight sessions. Similar cases are described by Roelants et al. (2004). Training sessions took place three times a week over 24 weeks. Two participants developed knee pain and had to stop the intervention. Moreover, it is known that during SR-WBV in a deep squat position, a local fatigue of the legs occurs that is caused by an increase in lactate and neuromuscular fatigue. Immediately after SR-WBV median lactate levels of $4.2 \mathrm{mmol} / 1$ have been measured in an unpublished study (Kessler, Schor, \& Radlinger, 2005). Reduced muscle stiffness due to a presynaptic inhibition of alpha motor neurons, i.e. a Renshaw inhibition could be considered possible causes of neuromuscular fatigue (Haas et al., 2004). The mechanical load on the tissue increases due to the lack of neuromuscular control. This results in an overloading of tissues and may lead to damages in muscle-tendon tissues and results in an increased level of glutamate (Kjaer, 2004). The neurotransmitter glutamate is a potent pain modulator in human central nervous system (Kjaer, 2004). In the next study the standing position on the WBV device should be adjusted accordingly.

The SR-WBV interventions were carried out during breaks or directly after the lectures. The scheduling appears to be suitable. The participants are on site at the university and could perform their intervention. Since one participant had discontinued the physiotherapy study, it was not possible for her to get to the university for a ten-minute intervention.

Statistics in feasibility studies should not be overrated but interpreted with caution. Summarising the effect after SRWBV intervention of this feasibility study provides first estimates for the secondary outcome (Bauhofer et al., 2001). The current study revealed that 10 days of SR-WBV intervention did not statistically influence IMVC, IRFD and DJ. In their systematic review, Nordlund and Thorstensson (2007) described strength improvements and better jump performance after WBV. They reported changes in muscle strength up to $24.4 \%$ and in jump performance up to $31.6 \%$ after S-WBV. Furthermore, in their two Meta-analyses, Marin and Rhea (2010a, 2010b) found improvements in muscle strength (leg press $+29 \%$, knee extension $+25 \%$ ) and power (vertical platforms: $\mathrm{ES}=.99$ and oscillating platforms: ES $=.36$ ) after S-WBV. Apart from muscle hypertrophy, the adaption to the nervous system after strength training stimulus plays an important role. The human body reacts with adaption to slow or fast muscle contractions (Schmidtbleicher, 1992). It is not only long-lasting heavy-resistance training which increases muscle strength or power, but also moderate strength exercise and sensorimotor exercises (Gruber \& Gollhofer, 2004; Gruber et al., 2007).

The results of the MVC, RFD and F-SSC of the current study did not confirm the findings of the review articles of Nordlund and Thorstensson (2007) as well as Marin and Rhea (2010a, 2010b). The following reason can be mentioned: First of all, a static position of 100 degrees knee flexion was hold for about 60 seconds. This position is similar to a squat during downhill skiing (Hydren, Volek, M., A., \& Kraemer, 2013). This isometric position of the leg muscles promotes muscular endurance (Lottmann, 2002) and not strength or power. This outcome variable was not measured. In future studies this outcome variable could be measured to evaluate muscular endurance. For this reason, the IRFD decreased in the SR-WBV group.

Secondly, to specifically train IMVC and IRFD, the training implementation needs to be redefined in the upcoming study. Delecluse et al. (2003) described improvements in muscle strength after S-WBV training triggered by reflex 
muscle contraction. For this reason, the exercises should be done more dynamically (Zatsiorsky, 2003) from 0 to 90 degrees knee flexion for a maximum of 60 seconds. Also, the strength and power training should be carried out with additional weights of $30 \%$ of 1 RM. Burd al. (Burd, Mitchell, Churchward-Venne, \& Phillips, 2012) postulated that low intensities exercise with additional weights $30 \%$ of $1 \mathrm{RM}$, stimulate muscle protein synthesis rates.

Thirdly, the DJ tests and the coordinative difficulties to perform correct F-SSC must be practised intensively. The DJ is difficult to perform. Chu (1998) emphasizes that to achieve the maximum result in jumps, the execution technic plays an important role. In addition, in order to exclude learning effects, the participants have to practise it until they perform the DJ correctly before measurements of the F-SSC are made. During DJ for F-SSC the calf muscles or the M. quadriceps can be activated in dependence of the angle position of the knee and the ankle. In this study, the VJH and GCT during a F-SSC, where the calf muscle is strongly loaded, was measured. However, the calf muscles were not exercised in this study. In the upcoming study, during SR-WBV additionally training should be done with calf raised. To get the F-SSC of the quadriceps muscle, more knee flexion must be made during the DJ.

\section{Conclusion}

The current feasibility study suggests that the study protocol is feasible with modification. Future studies must take into account that the process of recruitment should consist of several information sessions, to guarantee that all students will participate. In addition, the participants must be able to familiarise themselves with the DJ, which is a very fast complex movement and coordinative demanding, to get a real cycle in the combination of eccentric and concentric muscle action forms. Only when the participants are able to exercise the DJ very well, should measurements be carried out. Furthermore, the initial position must be adjusted (less flexion). Static positions over a longer period promote strength endurance of the muscles, although muscle strength and power have to be addressed. For this reason, exercises might be performed dynamically and with additional weights.

\section{Acknowledgements}

We thank the students for their efforts.

\section{Conflict of interest}

No conflicts of interest exist.

\section{References}

Aagaard, P., \& Bangsbo, J. (2006). The muscular system: design, function, and performance relationships. In M. N. S. C. M. Tipton, C. A. Tate, \& R. L. Terjung (Ed.), ACSM's advanced exercise physiology. Baltimore, MD: Lippincott Williams \& Wilkins.

Bauhofer, A., Stinner, B., Plaul, U., Torossian, A., Middeke, M., Celik, I., Koller, M., \& Lorenz, W. (2001). Quality of life and the McPeek recovery index as a new outcome concept for sepsis trials tested in a pilot study of granulocyte colony-stimulating factor in patients with colorectal cancer. British Journal of Surgery, 88, 1147.

Bogaerts, A. C., Delecluse, C., Claessens, A. L., Troosters, T., Boonen, S., \& Verschueren, S. M. (2009). Effects of whole body vibration training on cardiorespiratory fitness and muscle strength in older individuals (a 1-year randomised controlled trial). Age Ageing, 38(4), 448-454. doi: 10.1093/ageing/afp067

Bosco, C., Colli, R., Introini, E., Cardinale, M., Tsarpela, O., Madella, A., Tihanyi, J., \& Viru, A. (1999). Adaptive responses of human skeletal muscle to vibration exposure. Clin Physiol, 19(2), 183-187.

Burd, N. A., Mitchell, C. J., Churchward-Venne, T. A., \& Phillips, S. M. (2012). Bigger weights may not be get bigger muscles: evidence from acute muscle protein synthetic responses after resistance exercise. Appl Physiol Nutr Metab, 37(3), 551-554. doi: 10.1139/h2012-022

Burrows, R. F., Gan, E. T., Gallus, A. S., Wallace, E. M., \& Burrows, E. A. (2001). A randomised double-blind placebo controlled trial of low molecular weight heparin as prophylaxis in preventing venous thrombolic events after caesarean section: a pilot study. BJOG, 108(8), 835-839.

Cardinale, M., \& Bosco, C. (2003). The use of vibration as an exercise intervention. Exerc Sport Sci Rev, 31(1), 3-7.

Chu, A. D. (1998). Jumping into plyometrics (2 ed.): Human Kinetics Publishers.

Cochrane, D. J. (2011). Vibration exercise: the potential benefits. Int J Sports Med, 32(2), 75-99. doi: 10.1055/s-00301268010

Cochrane, D. J., Loram, I. D., Stannard, S. R., \& Rittweger, J. (2009). Changes in joint angle, muscle-tendon complex length, muscle contractile tissue displacement, and modulation of EMG activity during acute whole-body vibration. Muscle Nerve, 40(3), 420-429. doi: 10.1002/mus.21330

Corder, G. W., \& Foreman, D. I. (2009). Nonparametric statistics for non-statisticans a step-by-step approach. Hoboken, New Jersey: John Wiley \& Sons. Inc. 
Cormie, P., Deane, R. S., Triplett, N. T., \& McBride, J. M. (2006). Acute effects of whole-body vibration on muscle activity, strength, and power. J Strength Cond Res, 20(2), 257-261. doi: 10.1519/R-17835.1

Craig, P., Dieppe, P., Macintyre, S., Michie, S., Nazareth, I., Petticrew, M., \& Medical Research Council, Guidance. (2008). Developing and evaluating complex interventions: the new Medical Research Council guidance. BMJ, 337, a1655. doi: 10.1136/bmj.a1655

de Ruiter, C. J., Van Raak, S. M., Schilperoort, J. V., Hollander, A. P., \& de Haan, A. (2003). The effects of 11 weeks whole body vibration training on jump height, contractile properties and activation of human knee extensors. Eur J Appl Physiol, 90(5-6), 595-600. doi: 10.1007/s00421-003-0931-2

Delecluse, C., Roelants, M., \& Verschueren, S. (2003). Strength increase after whole-body vibration compared with resistance training. Med Sci Sports Exerc, 35(6), 1033-1041. doi: 10.1249/01.MSS.0000069752.96438.B0

Faul F, Erdfelder E, Lang, AG., \& Buchner A. (2003). G*Power 3: A flexible statistical power analysis for the social, behavioural, and biomedical sciences. Behaviour Research Methods, 39:175-191.

Gruber, M., \& Gollhofer, A. (2004). Impact of sensorimotor training on the rate of force development and neural activation. Eur J Appl Physiol, 92(1-2), 98-105. doi: 10.1007/s00421-004-1080-y

Gruber, M., Gruber, S. B., Taube, W., Schubert, M., Beck, S. C., \& Gollhofer, A. (2007). Differential effects of ballistic versus sensorimotor training on rate of force development and neural activation in humans. J Strength Cond Res, 21(1), 274-282. doi: 10.1519/R-20085.1

Haas, C. T. (2006). [Proprioception und injury prevention]. Sportphysiotherapie aktuell, 20, 107-111.

Haas, C. T., Buhlmann, A., Turbanski, S., \& Schmidtbleicher, D. (2006). Proprioceptive and sensorimotor performance in Parkinson's disease. Res Sports Med, 14(4), 273-287.

Haas, C. T., Turbanski, S., Kaiser, I., \& Schmidtbleicher, D. (2004). [Biomechanical and physiological effects of mechanical vibration stimuli in humans]. Deutsche Zeitschrift für Sportmedizin, 55(2), 34-43.

Haas, C. T., Turbanski, S., Kessler, K., \& Schmidtbleicher, D. (2006). The effects of random whole-body-vibration on motor symptoms in Parkinson's disease. NeuroRehabilitation, 21(1), 29-36.

Haas, C. T., Turbanski, S., \& Schmidtbleicher, D. (2002). Zum Einsatz randomisierter Oszillationen in der Prävention und Rehabilitation von Rupturen des vorderen Kreuzbandes im alpinen Skirennlauf. Institut für Sportwissenschaften. J.W. Unpublished work. Goethe-Universität Frankfurt am Main. Frankfurt am Main.

Haas, C. T., Turbanski, S., \& Schmidtbleicher, D. (2007). [Vibration training in the rehabilitation of gait and balance disorders]. Focus Neurogeriatrie, 1(3), 18-19.

Hydren, J. R., Volek, J.S., M., Maresh; C., A., Comstock. B., \& Kraemer, W. J. (2013). Review of strength and conditioning for alpine ski racing. Strength and Conditional Journal, 35(1), 10-28.

Kawamori, N., \& Haff, G. G. (2004). The optimal training load for the development of muscular power. $J$ Strength Cond Res, 18(3), 675-684.

Kessler, J., Schor, S., \& Radlinger, L. (2005). Die kardivaskuläre und metabolische Beanspruchung auf dem Zeptor. Unpublished Diploma Thesis. University of Applied Sciences, Bern.

Kjaer, M. (2004). Role of extracellular matrix in adaptation of tendon and skeletal muscle to mechanical loading. Physiol Rev, 84(2), 649-698. doi: 10.1152/physrev.00031.2003

Knuttgen, H. G, \& Komi, P.V. (2003). Basic considerationts for exerceise. In P. V. Komi (Ed.), Strength and power in sport (2 ed., pp. 3-10). Oxford: Blackwell Science Ltd.

Lancaster, G.A., Dodd, S., \& Williamson, P.R. (2002). Design and analysis of pilot studies: recommendations for good practice. Journal of Evaluation in Clinical Practice, 10(2), 307-312.

Lottmann, A. (2002). Untersuchungen zur Optimierung der Belastungsteuerung im Krafttraining durch Kombination verschiedener Methoden der trainingsbegleitenden Leistungsdiagnostik. (PhD), Universität Göttingen.

Marin, P. J., Bunker, D., Rhea, M. R., \& Ayllon, F. N. (2009). Neuromuscular activity during whole-body vibration of different amplitudes and footwear conditions: implications for prescription of vibratory stimulation. $J$ Strength Cond Res, 23(8), 2311-2316. doi: 10.1519/JSC.0b013e3181b8d637

Marin, P. J., \& Rhea, M. R. (2010a). Effects of vibration training on muscle power: a meta-analysis. $J$ Strength Cond Res, 24(3), 871-878. doi: 10.1519/JSC.0b013e3181c7c6f0

Marin, P. J., \& Rhea, M. R. (2010b). Effects of vibration training on muscle strength: a meta-analysis. $J$ Strength Cond Res, 24(2), 548-556. doi: 10.1519/JSC.0b013e3181c09d22

Mebes, C., Amstutz, A., Luder, G., Ziswiler, H. R., Stettler, M., Villiger, P. M., \& Radlinger, L. (2008). Isometric rate of force development, maximum voluntary contraction, and balance in women with and without joint hypermobility. Arthritis Rheum, 59(11), 1665-1669. doi: 10.1002/art.24196 
Nordlund, M. M., \& Thorstensson, A. (2007). Strength training effects of whole-body vibration? Scand J Med Sci Sports, 17(1), 12-17. doi: 10.1111/j.1600-0838.2006.00586.x

Rees, S. S., Murphy, A. J., \& Watsford, M. L. (2008). Effects of whole-body vibration exercise on lower-extremity muscle strength and power in an older population: a randomized clinical trial. Phys Ther, 88(4), 462-470. doi: $10.2522 /$ ptj.20070027

Roelants, M., Delecluse, C., Goris, M., \& Verschueren, S. (2004). Effects of 24 weeks of whole body vibration training on body composition and muscle strength in untrained females. Int J Sports Med, 25(1), 1-5. doi: 10.1055/s-2003-45238

Roelants, M., Delecluse, C., \& Verschueren, S. M. (2004). Whole-body-vibration training increases knee-extension strength and speed of movement in older women. $J$ Am Geriatr Soc, 52(6), 901-908. doi: 10.1111/j.15325415.2004.52256.x

Rogan, S., \& Hilfiker, R. (2012). [Training methods - increase muscle strength due to whole-body vibration - force with Hertz]. Sportverletzung Sportschaden, 26(4), 185-187.

Rogan, S., Hilfiker, R., Schmid, S., \& Radlinger, L. (2012). Stochastic resonance whole-body vibration training for chair rising performance on untrained elderly: a pilot study. Arch Gerontol Geriatr, 55(2), 468-473. doi: 10.1016/j.archger.2012.02.011

Rogan, S., Radlinger, L., Schmid, S., Herren, K., Hilfiker, R., \& de Bruin, ED. (2012). Skilling up for training: a feasibility study investigating acute effects of stochastic resonance whole-body vibration on postural control of older adults. Ageing Research, 3(1), e5.

Scherfer, E. (2006). Forschung verstehen. München: Pflaum Verlag.

Schlumberger, A., \& Schmidtbleicher, D. (2000). [Basics of strength diagnostics in prevention and rehabilitation]. Manuelle Medizin, 38.

Schmidtbleicher, D. (1992). Training for power events. In P. V. Komi (Ed.), Strength and Power in Sports. Vol. III of the Encyclopeadia of Sports Medicine of IOC (pp. 381-395). Oxford: Blackwell Scientific Publications.

Thabane, L., Ma, J., Chu, R., Cheng, J., Ismaila, A., Rios, L. P., Robson, R., Thabane, M., Giangregorio L, \& Goldsmith, C. H. (2010). A tutorial on pilot studies: the what, why and how. BMC Med Res Methodol, 10, 1. doi: 10.1186/1471-2288-10-1

Turbanski, S., Haas, C. T., Schmidtbleicher, D., Friedrich, A., \& Duisberg, P. (2005). Effects of random whole-body vibration on postural control in Parkinson's disease. Res Sports Med, 13(3), 243-256.

Viitasalo, J. T., Salo, A., \& Lahtinen, J. (1998). Neuromuscular functioning of athletes and non-athletes in the drop jump. Eur J Appl Physiol Occup Physiol, 78(5), 432-440.

Voelzke, M., Stutzig, N., Thorhauer, H. A., \& Granacher, U. (2012). Promoting lower extremity strength in elite volleyball players: effects of two combined training methods. J Sci Med Sport, 15(5), 457-462. doi: 10.1016/j.jsams.2012.02.004

Zatsiorsky, V. (2003). Biomechanics of strength and strength training. In P. V. Kuomi (Ed.), Strength and power in sports (2 ed., pp. 439-487). Oxford: Blackwell Science Ltd. 